\title{
Absorbable stent: focus on clinical applications and benefits
}

This article was published in the following Dove Press journal:

Vascular Health and Risk Management

28 February 2012

Number of times this article has been viewed

\author{
Nieves Gonzalo \\ Carlos Macaya \\ Interventional Cardiology, \\ Cardiovascular Institute, Hospital \\ Clinico San Carlos, Instituto de \\ Investigación Sanitaria del Hospital \\ Clinico San Carlos, Madrid, Spain
}

Correspondence: Nieves Gonzalo Interventional Cardiology, Cardiovascular Institute, Hospital Clínico San Carlos, 28040 Madrid, Spain

Email nieves_gonzalo@yahoo.es
Abstract: Coronary stents have improved very significantly the immediate and long-term results of percutaneous coronary interventions. However, once the vessel has healed, the scaffolding function of the stent is no longer needed, and the presence of a permanent metallic prosthesis poses important disadvantages. This has led to the idea of creating new devices that are able to provide mechanical support for a determined period and then disappear from the vessel, allowing its natural healing and avoiding the risks associated with having a permanent metallic cage, such as stent thrombosis. Absorbable stents currently appear as one of the most promising fields in interventional cardiology. The present article will review the available clinical evidence regarding these devices at present and their future perspectives.

Keywords: absorbable stent, bioresorbable stent, absorb, percutaneous coronary intervention

\section{Introduction}

The interventional treatment of coronary atherosclerosis has changed and improved significantly in the last years. The initial technique, balloon angioplasty, faced the important problems of acute recoil and acute vessel occlusion due to the dissection flaps created by the balloon. ${ }^{1-3}$ Coronary stents were created to overcome these issues. The initial design, bare-metal stents, were able to almost eliminate acute recoil and vessel occlusion and decreased restenosis by preventing negative remodeling. ${ }^{45}$ However, their efficacy was reduced by the induction of an intense neoproliferative response in the vessel, which was another cause of restenosis in these devices. ${ }^{6}$ Drug-eluting stents, incorporating an antiproliferative drug, reduced the rates of restenosis, but they can be associated with an irregular endothelialization, requiring prolonged double antiplatelet therapy to reduce the risk of late and very late stent thrombosis. ${ }^{7-10}$ All the aforementioned limitations led to the idea of creating new devices that are able to provide mechanical support while it is needed and then disappear from the vessel, allowing its natural healing and avoiding the risks associated with having a permanent metallic cage. ${ }^{11,12}$ Absorbable stents currently appear as one of the most promising fields in interventional cardiology. The present article will review the available clinical evidence regarding these devices at present and their future perspectives.

\section{Rationale for absorbable stents in treating coronary artery disease}

Coronary stents have improved very significantly the immediate and long-term results of percutaneous coronary interventions (PCIs). However, once the vessel has healed, 
the scaffolding function of the stent is no longer needed, and the presence of a permanent metallic prosthesis poses important disadvantages. Bioresorbable stents are a field of growing interest in interventional cardiology because of their potential benefits, including the decreased risk of stent thrombosis at long-term follow-up, one of the most feared complications of metallic stents. ${ }^{13}$ The sustained inflammation attributed to the presence of a permanent foreign body in the vessel wall involved in the pathogenesis of stent thrombosis and recently also in the generation of new atherosclerosis might be avoided by using a resorbable scaffold. ${ }^{14-16}$ If the stent disappears, there would not be the possibility of late malapposition, another of the features involved in stent thrombosis. ${ }^{17}$ Once the device disappears, the patient would not need prolonged double antiplatelet therapy, thereby decreasing the risk of bleeding, especially in older patients. The absorption of the stent could potentially lead to a recovery of the endothelial function of the vessel, making it responsive again to vasoactive agents. Further, the artery would not be permanently caged, and late positive remodeling in response to a physiological stimulus would be possible. Theoretically, an absorbable stent made of a polymer could be more flexible and conformable and would influence the shear stress pattern less than a permanent metallic prosthesis. It has been demonstrated that the shear stress pattern influences the neointima distribution after stent implantation. ${ }^{18,19}$ The disappearance of the prosthesis would allow future treatments in the vessel if needed (either percutaneous or surgical) and would facilitate the access to side branches initially jailed by the stent. These aspects are of special interest in children, in whom the vessel growth can create a mismatch between the originally implanted prosthesis and the vessel size. Further, depending on their composition, some of these devices could be followed with noninvasive techniques such as multislice computed tomography (MSCT) scan because they do not create the artifacts originated by metallic stents. Finally, many patients are concerned about having a permanent implant in their coronary arteries and would prefer a device that is able to disappear after a determined period (Table 1).

\section{Bioabsorbable stent design}

With all the aforementioned potential advantages, the concept of bioresorbable stents has created interest for a long time, but technical challenges have made the development of these devices slow. The ideal design should have mechanical properties that are able to provide the necessary vessel support
Table I Potential advantages of bioresorbable scaffolds (BRS) over bare-metal stents (BMS) and drug-eluting stents (DES)

\begin{tabular}{|c|c|c|c|}
\hline Advantage & BRS & BMS & DES \\
\hline Radial support & Transient & Permanent & Permanent \\
\hline $\begin{array}{l}\text { Need for prolonged } \\
\text { double antiplatelet therapy }\end{array}$ & No & No & Yes \\
\hline Late stent thrombosis & No & Yes & Yes \\
\hline $\begin{array}{l}\text { Expansive remodeling } \\
\text { possible }\end{array}$ & Yes & No & No \\
\hline $\begin{array}{l}\text { Follow-up with } \\
\text { noninvasive techniques }\end{array}$ & Yes & No & No \\
\hline $\begin{array}{l}\text { Permanent jailing of side } \\
\text { branches }\end{array}$ & No & Yes & Yes \\
\hline $\begin{array}{l}\text { Facilitate reintervention } \\
\text { in the treated segment } \\
(\mathrm{CABG} \text { or } \mathrm{PCl})\end{array}$ & Yes & No & No \\
\hline $\begin{array}{l}\text { Potential recovery of } \\
\text { the endothelial function }\end{array}$ & Yes & No & No \\
\hline
\end{tabular}

Abbreviations: $\mathrm{CABG}$, coronary artery bypass surgery; $\mathrm{PCl}$, percutaneous coronary intervention.

during the required period, must be biocompatible, and should have an adequate degradation time, disappearing without creating an intense inflammatory response. Apart from that, the device has to have good deliverability, and, ideally, it should be able to carry an antiproliferative drug in order to reduce restenosis. ${ }^{20}$ Both the selection of the material and the design are going to influence the success of the device. Regarding the material, there are two possibilities that are being tested: polymer-based materials that are degraded by hydrolysis, and absorbable metals such as magnesium-based alloys. Among the polymers, the one that has been used more frequently is polylactide (PLLA), which degrades via the Krebs cycle to water and carbon dioxide. Both polymers and magnesium alloys are less stiff than conventional metallic stents, and several modifications in the material processing (such as polymer chain orientation, increases in the molecular weight, or length of the polymer chain) and strut design (thickness) are required to obtain an adequate radial support. The biocompatibility before, during, and following degradation is another important issue. In order to avoid inflammation or a toxic response in the vessel wall during degradation, the device should have as little material as possible, and the process should not occur too fast to allow an adequate response of the tissue to the products of degradation. The vessel response to degradation can also be different, depending on the underlying plaque and on the presence of antiproliferative drug. Finally, in order to be introduced in the catheterization laboratories, bioabsorbable devices should be easy to store (avoiding, if possible, the need for refrigeration), should 
have good deliverability, and should be easy to position in the coronary artery. The majority of bioabsorbable materials have low radio-opacity, but the visualization of the device under fluoroscopy can be increased by the use of radio-opaque markers in the balloon or in the device itself. ${ }^{12,21}$

\section{Everolimus-eluting PLLA scaffold}

Different bioabsorbable coronary stents have been tested in clinical trials. In this paper, we will focus on the everolimus-eluting PLLA scaffold (BVS) (Abbot Vascular, Santa Clara, CA), which has the most advanced clinical program, and will review briefly the clinical evidence for the other bioabsorbable coronary stents.

\section{BVS design}

The BVS has a bioabsorbable polymer backbone of PLLA with a polymer coating of poly-D,L-lactide, which contains and controls the release of the antiproliferative drug (everolimus). PLLA is a biocompatible material used widely in medicine. The polymer is degraded by hydrolysis into water, carbon dioxide, and lactic acid. The dose and release pattern of the everolimus is the same one used for the Xience
V stent (Abbot Vascular). The scaffold is balloon expandable, radiolucent, and has two radio-opaque markers in its distal ends to facilitate its positioning in the coronary artery.

There are two designs of the BVS that have been tried in clinical trials. In Cohort A of the ABSORB (A Clinical Evaluation of the Bioabsorbable Everolimus Eluting Coronary Stent System in the Treatment of Patients With de Novo Native Coronary Artery Lesions) trial, the design was the BVS 1.0. This scaffold has a circumferential out-of-phase zigzag hoops design and provided radial support to the vessel for only weeks, having an absorption time of approximately 2 years. ${ }^{22}$ The new version used in Cohort B (BVS 1.1) has modifications in the platform design (in-phase zigzag hoops linked by bridges) and in polymer processing, in order to improve the mechanical strength and to reduce early and late recoil. The degradation process is slower in the second version to provide longer mechanical support to the vessel. ${ }^{23}$

\section{BVS clinical results}

The available clinical results of the performance of the BVS come from the ABSORB trial (Figure 1). ABSORB Cohort A was a single-arm, prospective, open-label, first-in-humans

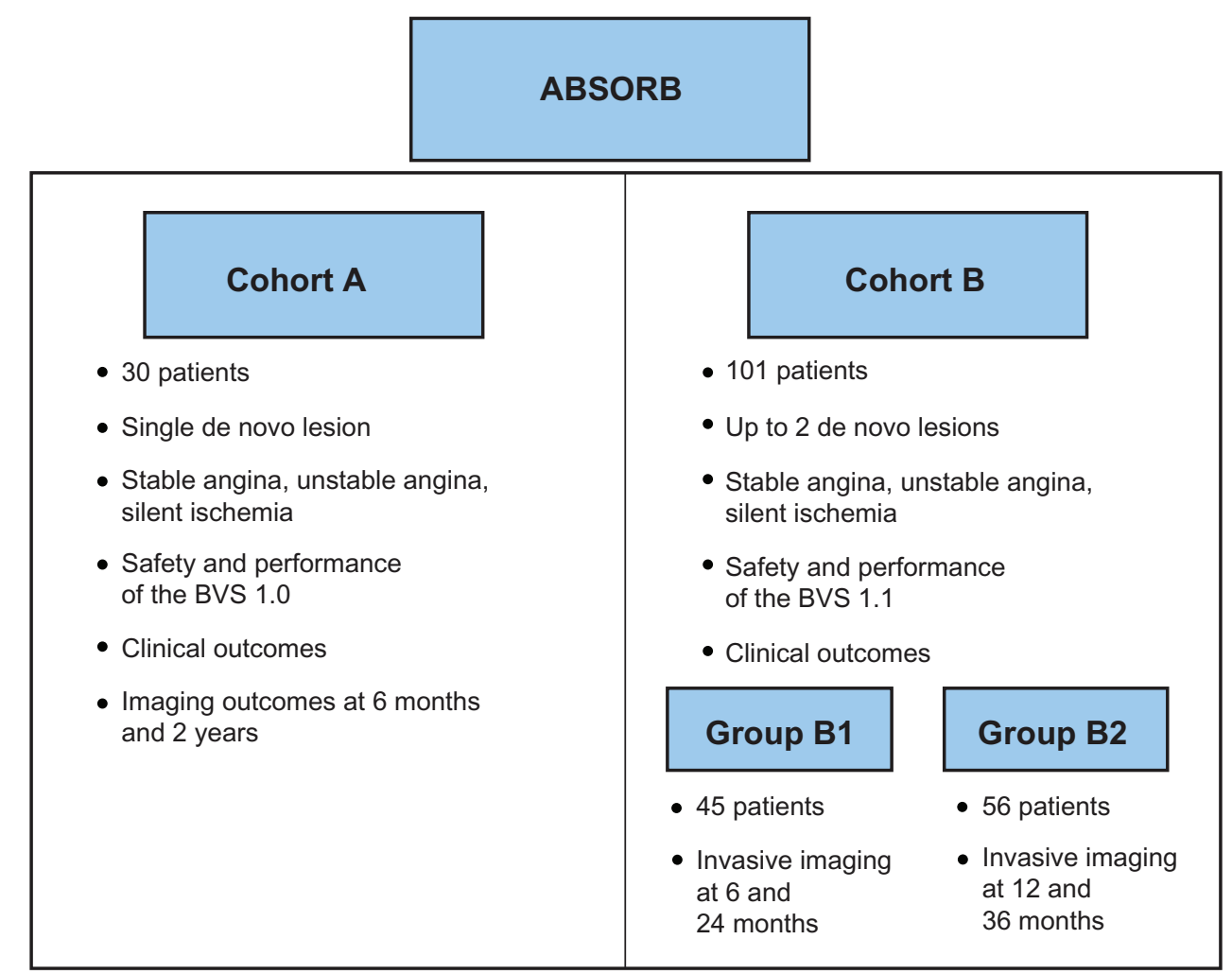

Figure I Overview of the ABSORB (A Clinical Evaluation of the Bioabsorbable Everolimus Eluting Coronary Stent System in the Treatment of Patients With de Novo Native Coronary Artery Lesions) Cohort A and B trials.

Abbreviation: BVS, everolimus-eluting polylactide scaffold. 
study with safety and imaging endpoints. Between March 2006 and July 2006, Cohort A enrolled 30 patients with stable angina, unstable angina, or silent ischemia and a single de novo lesion in a native coronary artery of $3.0 \mathrm{~mm}$. Patients were treated with the BVS 1.0 version, and there were two available stent lengths (12 $\mathrm{mm}$ and $18 \mathrm{~mm})$. Clinical endpoints were cardiac death, myocardial infarction (MI), ischemia-driven target lesion revascularization (TLR), ischemia-driven major adverse cardiac event (MACE) (composite of cardiac death, MI, or ischemia-driven TLR), and stent thrombosis. We now have clinical results up to 4 years for Cohort A (29 of the 30 patients have follow-up). There was only one non-Q-wave MI related to the treatment of a nontarget stenosis in a patient with a BVS implanted 46 days earlier, resulting in an MACE rate of 3.4\% ${ }^{24}$ There were no cases of cardiac death or scaffold thrombosis up to 4 years. This MACE rate has remained unchanged from the 6-month follow-up. ${ }^{11,22,25}$

The ABSORB Cohort B trial is a multicenter, single-arm trial assessing the safety and performance of the BVS (Rev.1.1, Abbott Vascular) in the treatment of patients with stable angina, unstable angina, or silent ischemia and a maximum of two de novo native coronary artery lesions with a maximum diameter of $3.0 \mathrm{~mm}$ and a length of $\leq 14 \mathrm{~mm}$. The clinical endpoints were similar to Cohort A. The trial enrolled 101 patients, 45 of whom (Group B1) were randomized to angiographic and invasive imaging at 6-month and 24-month follow-up, and 56 of whom (Group B2) were randomized to invasive follow-up at 12 months and 36 months. At 6-month follow-up there were no cases of cardiac death or scaffold thrombosis, and the ischemia-driven MACE rate was five out of 101 (4.9\%), three non-Q-wave MIs, and two ischemia-driven PCIs. Interestingly, there were no differences in MACE between vessels $<2.5 \mathrm{~mm}$ or $>2.5 \mathrm{~mm}$ (three of 41 [7.3\%] cases in small vessels vs two of 60 [3.3\%] in large vessel cases; $P=0.3933) .{ }^{26}$ In Group B2 at 12-month follow-up there were two non-Q-wave MIs (one periprocedural and one iatrogenic) and two ischemia-driven TLRs, resulting in a MACE of 7.1\% (four of 56). ${ }^{27}$ The 2-year follow-up of Cohort B1 (45 patients) has recently been presented, showing a MACE rate of $6.8 \%$ (one non-Q-wave MI and two ischemia-driven TLRs), which is unchanged from the 6-month and 1-year follow-ups, with no cases of scaffold thrombosis or cardiac death. ${ }^{28}$

\section{BVS imaging results}

The BVS is probably the coronary device that has been studied with more detail in the history of coronary interventions through multiple different invasive and noninvasive imaging modalities. In this section we will review the imaging results of the Absorb trial.

\section{Invasive BVS assessment \\ Angiography}

In Cohort A, 2-year angiography showed an in-stent late loss of $0.48 \pm 0.28 \mathrm{~mm}$, similar to the results at 6 months. ${ }^{11}$ In Cohort B, the late loss was $0.19 \pm 0.18 \mathrm{~mm}$ at 6 months for Group B1 and $0.27 \pm 0.32 \mathrm{~mm}$ at 12 months for Group B2. This late loss at 12 months is comparable with that observed in historical series of metallic everolimus-eluting stents, with a very low restenosis rate. ${ }^{27}$

\section{Intravascular ultrasound and derived techniques}

The quantitative intravascular ultrasound (IVUS) evaluation in Cohort $\mathrm{A}$ at 6 months revealed a reduction of $12 \%$ in the scaffold area without vessel shrinkage, suggesting an early recoil phenomenon. This, in addition to intimal hyperplastic tissue, resulted in a $16.8 \%$ reduction in luminal area. $^{22}$ The 2-year follow-up IVUS showed a significant increase in minimal and mean luminal area and a decrease in plaque area, without changes in the vessel area between 6 months and 2 years. ${ }^{11}$ In Cohort A (BVS 1.0), the scaffold was not discernible at 2 years and could not be measured. In Cohort B (BVS 1.1), the scaffold remained detectable by IVUS for up to 2 years. At 6 months, in Group B1 there was no significant change in vessel area and a small decrease in mean scaffold area, minimal scaffold area, mean lumen area, and minimum lumen area. The decrease in the mean scaffold area was $2 \%$ versus the $12 \%$ observed in Cohort $A$ at 6 months, demonstrating the improved mechanical properties of the BVS 1.1 version. ${ }^{29}$ The neointimal growth was very small, reflecting the effect of the antiproliferative drug. At 1-year follow-up, Cohort B2 showed no changes in the scaffold area and mean lumen area, with a decrease of $1.94 \%$ in the minimum lumen area. ${ }^{27}$ The 2 -year results in Group B1 showed a modest but significant increase in the vessel area, scaffold area, lumen area, and plaque area from 6 months to 2 years. $^{28}$

IVUS-derived techniques such as IVUS virtual histology (VH) and echogenicity have been used to evaluate the absorption of the scaffold..$^{30-33}$ The decrease in dense calcium in IVUS-VH and the reduction of hyperechogenic tissue in echogenicity analysis have been proposed as surrogate markers of ultrasonic alteration of the polymeric struts. In Cohort A, there was a progressive reduction of hyperechogenic tissue from the implantation until 2-year follow-up, but the dense calcium by $\mathrm{VH}$ remained unchanged. ${ }^{11}$ In Cohort B1, 
at 6 months, there were no significant changes in dense calcium. ${ }^{29}$ However, in Cohort B2, at 12 months, there was a significant decrease in calcium by $\mathrm{VH}$ and in tissue echogenicity. ${ }^{27}$

\section{Optical coherence tomography}

Optical coherence tomography (OCT) has been one of the most useful techniques for evaluating the behavior of bioresorbable scaffolds. Apart from giving measurements of the lumen and scaffold and assessing in a precise way the apposition and coverage of the scaffold, OCT has provided unique insights into the changes of the polymeric struts over time. The polymeric struts show in OCT a black box appearance without shadow. This is very different from metallic struts, which appear as highly reflective structures with dorsal shadow. In Cohort A, it was possible to observe important changes in the strut morphology by OCT at 6 months (and a classification of the different morphologies observed was proposed), whereas at 2 years a high proportion of the struts were indiscernible by OCT. ${ }^{11}$ In Cohort B, however, the majority of the struts remain visible with a typical box appearance at 1-year follow-up, but a decrease in their black core size has been demonstrated and interpreted as an early sign of resorption. ${ }^{27}$ In order to understand the meaning of the changes in the polymeric struts observed with OCT, a recent study compared the OCT findings with corresponding histology in a porcine coronary artery model immediately after and at 28 days, 2 years, 3 years, and 4 years after BVS implantation. The study demonstrated that the majority of struts still visible by OCT at 2 years were largely resorbed, and the image in OCT corresponded to the filling of the previous location of the strut with connective tissue. OCT was therefore reflecting the integration of the struts in the surrounding tissue rather than the absorption process. ${ }^{34}$

Regarding the evaluation of malposition and coverage in Cohort A, at 2 years, OCT demonstrated that all the struts were covered, and the cases of malposition detected at 6 months were resolved. ${ }^{11}$ In Cohort B1, similar results have been shown at 2 years, with an almost complete coverage of all the struts and a resolution of the majority of cases of malposition initially observed. ${ }^{28}$ Regarding the quantitative OCT evaluation in Cohort A, the results were similar to IVUS, demonstrating an initial decrease in lumen area at 6 months with a subsequent increase at 2 years. ${ }^{11}$ At 1 -year follow-up in Cohort B2, mean and minimal scaffold area by OCT did not change (again reflecting the improved mechanical strength of the BVS 1.1). The mean and minimal lumen area decreased by $18.1 \%$ and $23.4 \%$ due to mild neointimal growth. ${ }^{27}$ At 2-year follow-up in Group B1, OCT demonstrated an increase in scaffold area and a small decrease in the mean and minimal lumen area, related to a slight increase in the neointimal area, which remained very low. ${ }^{28}$ These results reflect the good mechanical performance of the BVS 1.1 and the well-controlled neointimal proliferation obtained with this device.

\section{Noninvasive BVS assessment}

Another potential advantage of bioabsorbable stents would be the possibility of being followed up with noninvasive imaging techniques such as MSCT scan. In Cohort A of the ABSORB trial, patients were followed up with MSCT at 18 months. MSCT was evaluated in 24 out of the 30 patients, demonstrating the feasibility of the technique to demonstrate stent patency and to measure mean lumen area, minimum lumen area, and percent area stenosis without the artifacts associated with metallic stents. ${ }^{11}$ MSCT has also been used for scaffold follow-up at 5 years in Cohort A and at 18 months in Cohort B.

\section{Vasomotion restoration}

It has been demonstrated that permanent metallic stenting suppresses vasomotion in the stented segment. ${ }^{35}$ In the ABSORB trial, the hypothesis of vasomotion recovery after scaffold absorption was tested. Two drugs were used in the study to evaluate vasomotion: methylergonovine (which induces nonendothelium-dependent vasoconstriction) and acetylcholine (Ach) (which induces endothelium-dependent direction of flow-mediated vasodilatation). The vasodilator response to Ach could therefore suggest the presence of functionally active endothelium. In Cohort A, at 2 years, five of nine patients tested with Ach showed vasodilatation at the site of the scaffold implantation. In Cohort B2, at 1-year follow-up, ten of 19 analyzable patients who received Ach showed vasoconstriction of the scaffolded segments, eight showed vasodilation, and one did not have any vasomotion. These results suggest that in the majority of patients there was not a complete recovery of the normal endothelium in the scaffolded segments at the time when follow-up was performed. $^{27}$

\section{Other bioabsorbable coronary stents \\ Igaki-Tamai stent}

This was the first fully bioabsorbable stent implanted in humans more than 10 years ago. It is composed of PLLA, 
has a degradation time of around 2 years, and does not have drug elution. The stent expanded by itself using heated contrast to inflate the delivery balloon. PLLA is radiolucent, and two markers are required for placement. In the first-in-human study, a total of 25 stents were successfully implanted in 19 lesions in 15 patients. At 30 days, no stent thrombosis and no major cardiac event occurred, and at 6 months there was only one repeat revascularization. ${ }^{36} \mathrm{~A}$ second study including 50 patients (63 lesions, 84 stents) also showed good clinical results, with a survival rate of $97.7 \%$ and an MACE-free rate of $82 \%{ }^{23}$ Even with these promising clinical results, the clinical use of the stent for coronary arteries did not extend, mainly because of the complex implantation procedure with the thermal balloon.

\section{Magnesium alloy stents}

Magnesium is a biocompatible metal and is common in the human body. The first generation of magnesium alloy stent (AMS-1; Biotronik, Berlin, Germany) was balloon expandable, did not have drug elution, and was radiolucent, showing good mechanical properties with radial strength at implantation similar to those of stainless steel stents. This stent was tested in the PROGRESS AMS (Clinical Performance and Angiographic Results of Coronary Stenting with Absorbable Metal Stents) trial, where 71 stents were implanted in 63 patients with simple de novo stenosis. The authors demonstrated that the stent was resorbed (at 4-month follow-up only small remnants of the original struts were visible in IVUS). Further, they showed a recovery of the vasodilator function after nitroglycerin in the treated segment. ${ }^{37}$ There were no deaths, MI, or stent thrombosis at 12 months, but the restenosis rate was high, with target vessel revascularization at 1 year of $45 \% .{ }^{38}$ IVUS analysis demonstrated that early recoil attributable to the loss of radial force from a too fast degradation was probably the cause of the high rates of restenosis in these stents. ${ }^{39}$ New developments in this field are oriented to prolong the degradation time to avoid the early recoil (AMS-2) and to incorporate drug elution in order to avoid excessive neointimal growth (AMS-3).

\section{Tyrosine polycarbonate polymer: REVA stent}

The REVA stent (Reva Medical Inc, San Diego, CA) is made of an absorbable tyrosine-derived polycarbonate polymer that metabolizes to amino acids, ethanol, and carbon dioxide. The polymer is impregnated with iodine to increase its radio-opacity. It is balloon expandable and the degradation time is around 2 years but depends on the molecular weight of the polymer. Preclinical studies demonstrated good mechanical properties with a good radial force. The stent that was nondrug eluting was tested first in humans in RESORB (REVA Endovascular Study of a Bioresorbable Coronary Stent), a prospective, nonrandomized, single-arm, safety study that enrolled 27 patients. The study showed a high TLR rate (66.7\%) between 4 months and 6 months due to focal mechanical failures. ${ }^{40}$ This has led to a new design, the ReZolve stent, which has improved robustness of the polymer and is able to elute sirolimus.

\section{Sirolimus-eluting-poly(anhydride ester) salicylic acid: the IDEAL stent}

The IDEAL stent (Bioabsorbable Therapeutics Inc, Menlo Park, CA) is a fully bioabsorbable sirolimus-eluting stent that also releases salicylic acid. This stent has both antiproliferative and anti-inflammatory properties. It is balloon expandable and the degradation time is 9-12 months. It degrades into salicylate, carbon dioxide, and water. The first-in-humans study with the stent (WHISPER [IDEAL Bioabsorbable Coronary Stent Platform Eluting Sirolimus] study) enrolled eleven patients. There was no evidence of acute or chronic recoil, but the neointimal growth was excessive. A new design is under development, with a new drug dosing and release pattern and modifications in the stent design. $^{41,42}$

\section{Conclusion}

Absorbable stents appear as one of the most promising fields in interventional cardiology, with several potential advantages over permanent metallic stents. Professor Serruys, one of the pioneers in PCIs, has named them "the fourth revolution" after balloon angioplasty, bare-metal stents, and drug-eluting stents. ${ }^{23}$ The ABSORB Cohort A and B trials have shown the safety and efficacy of the BVS in simple lesions in stable patients. Larger studies are required to evaluate the performance of the device in other clinical and angiographic scenarios. Further, the results of the absorbable scaffold need to be compared in randomized trials against the second-generation drug-eluting stents. Research in the field is active, and new trials are already planned to determine the place in therapy of these devices.

\section{Disclosure}

The authors have no conflicts of interest in this work. 


\section{References}

1. Gruntzig AR, Senning A, Siegenthaler WE. Nonoperative dilatation of coronary-artery stenosis: percutaneous transluminal coronary angioplasty. $N$ Engl J Med. 1979;301(2):61-68.

2. Serruys PW, Luijten HE, Beatt KJ, et al. Incidence of restenosis after successful coronary angioplasty: a time-related phenomenon. A quantitative angiographic study in 342 consecutive patients at 1,2, 3, and 4 months. Circulation. 1988;77(2):361-371.

3. Luo H, Nishioka T, Eigler NL, et al. Coronary artery restenosis after balloon angioplasty in humans is associated with circumferential coronary constriction. Arterioscler Thromb Vasc Biol. 1996;16(11): 1393-1398.

4. Serruys PW, de Jaegere P, Kiemeneij F, et al. A comparison of balloon-expandable-stent implantation with balloon angioplasty in patients with coronary artery disease. Benestent Study Group. N Engl J Med. 1994;331(8):489-495.

5. Rodriguez AE, Santaera O, Larribau M, et al. Coronary stenting decreases restenosis in lesions with early loss in luminal diameter 24 hours after successful PTCA. Circulation. 1995;91(5): 1397-1402.

6. Alfonso F, Zueco J, Cequier A, et al. A randomized comparison of repeat stenting with balloon angioplasty in patients with in-stent restenosis. J Am Coll Cardiol. 2003;42(5):796-805.

7. Morice MC, Serruys PW, Sousa JE, et al. A randomized comparison of a sirolimus-eluting stent with a standard stent for coronary revascularization. $N$ Engl J Med. 2002;346(23):1773-1780.

8. Wenaweser P, Daemen J, Zwahlen M, et al. Incidence and correlates of drug-eluting stent thrombosis in routine clinical practice. 4-year results from a large 2-institutional cohort study. J Am Coll Cardiol. 2008; 52(14):1134-1140.

9. Kukreja N, Onuma Y, Garcia-Garcia HM, et al. The risk of stent thrombosis in patients with acute coronary syndromes treated with bare-metal and drug-eluting stents. JACC Cardiovasc Interv. 2009; 2(6):534-541.

10. Moreno R, Fernandez C, Hernandez R, et al. Drug-eluting stent thrombosis: results from a pooled analysis including 10 randomized studies. J Am Coll Cardiol. 2005;45(6):954-959.

11. Serruys PW, Ormiston JA, Onuma Y, et al. A bioabsorbable everolimus-eluting coronary stent system (ABSORB): 2-year outcomes and results from multiple imaging methods. Lancet. 2009; 373(9667):897-910.

12. Ormiston JA, Serruys PW. Bioabsorbable coronary stents. Circ Cardiovasc Interv. 2009;2(3):255-260.

13. Finn AV, Joner M, Nakazawa G, et al. Pathological correlates of late drug-eluting stent thrombosis: strut coverage as a marker of endothelialization. Circulation. 2007;115(18):2435-2441.

14. Nakazawa G, Vorpahl M, Finn AV, et al. One step forward and two steps back with drug-eluting-stents: from preventing restenosis to causing late thrombosis and nouveau atherosclerosis. JACC Cardiovasc Imaging. 2009;2(5):625-628.

15. Nakazawa G, Otsuka F, Nakano M, et al. The pathology of neoatherosclerosis in human coronary implants bare-metal and drug-eluting stents. J Am Coll Cardiol. 2011;57(11):1314-1322.

16. Joner M, Finn AV, Farb A, et al. Pathology of drug-eluting stents in humans: delayed healing and late thrombotic risk. JAm Coll Cardiol.2006; 48(1):193-202.

17. Cook S, Wenaweser P, Togni M, et al. Incomplete stent apposition and very late stent thrombosis after drug-eluting stent implantation. Circulation. 2007;115(18):2426-2434.

18. Gijsen FJ, Oortman RM, Wentzel JJ, et al. Usefulness of shear stress pattern in predicting neointima distribution in sirolimus-eluting stents in coronary arteries. Am J Cardiol. 2003;92(11):1325-1328.

19. Gomez-Lara J, Garcia-Garcia HM, Onuma Y, et al. A comparison of the conformability of everolimus-eluting bioresorbable vascular scaffolds to metal platform coronary stents. JACC Cardiovasc Interv. 2010;3(11):1190-1198.
20. Berglund JGY, Wilcox JN. Challenges related to the development of bioabsorbable vascular stents. Euro Intervention. 2009;5(Suppl F): F72-F79.

21. Onuma Y, Ormiston J, Serruys PW. Bioresorbable scaffold technologies. Circ J. 2011;75(3):509-520.

22. Ormiston JA, Serruys PW, Regar E, et al. A bioabsorbable everolimuseluting coronary stent system for patients with single de-novo coronary artery lesions (ABSORB): a prospective open-label trial. Lancet. 2008; 371(9616):899-907.

23. Onuma Y, Serruys PW. Bioresorbable scaffold: the advent of a new era in percutaneous coronary and peripheral revascularization? Circulation. 2011;123(7):779-797.

24. Dudek D, Onuma Y, Ormiston JA, et al. Four-year clinical follow-up of the ABSORB everolimus-eluting bioresorbable vascular scaffold in patients with denovo coronary artery disease: the ABSORB trial. Euro Intervention. 2011;7(9):1060-1061.

25. Onuma Y, Serruys PW, Ormiston JA, et al. Three-year results of clinical follow-up after a bioresorbable everolimus-eluting scaffold in patients with de novo coronary artery disease: the ABSORB trial. Euro Intervention. 2010;6(4):447-453.

26. Diletti R, Onuma Y, Farooq V, et al. 6-month clinical outcomes following implantation of the bioresorbable everolimus-eluting vascular scaffold in vessels smaller or larger than $2.5 \mathrm{~mm}$. J Am Coll Cardiol. 2011;58(3):258-264.

27. Serruys PW, Onuma Y, Dudek D, et al. Evaluation of the second generation of a bioresorbable everolimus-eluting vascular scaffold for the treatment of de novo coronary artery stenosis: 12-month clinical and imaging outcomes. J Am Coll Cardiol. 2011;58(15): 1578-1588.

28. Serruys PW. TCT-245. ABSORB Cohort B trial: two year clinical and angiographic results of the ABSORB bioresorbable everolimus eluting vascular scaffold. J Am Coll Cardiol. 2011;58:66.

29. Serruys PW, Onuma Y, Ormiston JA, et al. Evaluation of the second generation of a bioresorbable everolimus drug-eluting vascular scaffold for treatment of de novo coronary artery stenosis: six-month clinical and imaging outcomes. Circulation. 2010;122(22):2301-2312.

30. Garcia-Garcia HM, Gonzalo N, Pawar R, et al. Assessment of the absorption process following bioabsorbable everolimus-eluting stent implantation: temporal changes in strain values and tissue composition using intravascular ultrasound radiofrequency data analysis. A substudy of the ABSORB clinical trial. Euro Intervention. 2009;4(4): 443-448.

31. Brugaletta S, Garcia-Garcia HM, Diletti R, et al. Comparison between the first and second generation bioresorbable vascular scaffolds: a six month virtual histology study. Euro Intervention. 2011;6(9): $1110-1116$

32. Brugaletta S, Gomez-Lara J, Garcia-Garcia HM, et al. Analysis of 1 year virtual histology changes in coronary plaque located behind the struts of the everolimus eluting bioresorbable vascular scaffold. Int $J$ Cardiovasc Imaging. Epub November 23, 2011.

33. Bruining $\mathrm{N}$, de Winter S, Roelandt JR, et al. Monitoring in vivo absorption of a drug-eluting bioabsorbable stent with intravascular ultrasound-derived parameters a feasibility study. JACC Cardiovasc Interv. 2010;3(4):449-456.

34. Onuma Y, Serruys PW, Perkins LE, et al. Intracoronary optical coherence tomography and histology at 1 month and 2, 3, and 4 years after implantation of everolimus-eluting bioresorbable vascular scaffolds in a porcine coronary artery model: an attempt to decipher the human optical coherence tomography images in the ABSORB trial. Circulation. 2010;122(22):2288-2300.

35. Maier W, Windecker S, Kung A, et al. Exercise-induced coronary artery vasodilation is not impaired by stent placement. Circulation. 2002;105(20): 2373-2377.

36. Tamai H, Igaki K, Kyo E, et al. Initial and 6-month results of biodegradable poly-1-lactic acid coronary stents in humans. Circulation. 2000;102(4): 399-404. 
37. Ghimire G, Spiro J, Kharbanda R, et al. Initial evidence for the return of coronary vasoreactivity following the absorption of bioabsorbable magnesium alloy coronary stents. Euro Intervention. 2009;4(4):481-484.

38. Erbel R, Di Mario C, Bartunek J, et al. Temporary scaffolding of coronary arteries with bioabsorbable magnesium stents: a prospective, non-randomised multicentre trial. Lancet. 2007;369(9576): 1869-1875.

39. Waksman R, Erbel R, Di Mario C, et al. Early- and long-term ultrasound and angiographic findings after bioabsorbable magnesium stent implantation in human coronary arteries. JACC Cardiovasc Interv. 2009;2(4):312-320.
40. Grube E. Bioabsorbable stent: the Boston Scientific and REVA technology. EuroPCR. May 19-22, 2009; Barcelona, Spain.

41. Jabara R, Chronos N, Robinson K. Novel bioabsorbable salicylate-based polymer as a drug-eluting stent coating. Catheter Cardiovasc Interv. 2008;72(2):186-194.

42. Jabara RPL, Geva S, Chen J, Chronos N, Robinson K. Novel fully bioabsorbable salicylate-based sirolimus eluting stent. Euro Intervention. 2009;Suppl F:F58-F64.

\section{Publish your work in this journal}

Vascular Health and Risk Management is an international, peerreviewed journal of therapeutics and risk management, focusing on concise rapid reporting of clinical studies on the processes involved in the maintenance of vascular health; the monitoring, prevention and treatment of vascular disease and its sequelae; and the involvement of metabolic disorders, particularly diabetes. This journal is indexed on PubMed Central and MedLine. The manuscript management system is completely online and includes a very quick and fair peer-review system, which is all easy to use. Visit http://www.dovepress.com/ testimonials.php to read real quotes from published authors. 